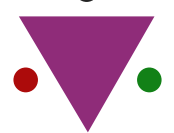

IJCRR

Section: Healthcare

Sci. Journal Impact

Factor: 6.1 (2018)

ICV: $90.90(2018)$

(c) (i) (9)

Copyright@IJCRR

\title{
Effect of Turmeric on Serum Malondialdehyde in Oral Submucous Fibrosis
}

\section{Tejashree D. Kapgate ${ }^{1}$, Rahul R. Bhowate², Suwarna Dangore², Mrunal Meshram ${ }^{3}$, Vidya K Lohe ${ }^{4}$}

\begin{abstract}
'MDS, Tutor, Department of Oral Medicine and Radiology, Sharad Pawar Dental College \& Hospital, Datta Meghe Institute of Medical Sciences (Deemed to be University), Sawangi (M), Wardha-442001, Maharashtra, India; ${ }^{2}$ MDS, MPhil, Professor, Department of Oral Medicine and Radiology, Sharad Pawar Dental College \& Hospital, Datta Meghe Institute of Medical Sciences (Deemed to be University), Sawangi (M), Wardha-442001, Maharashtra, India; ${ }^{3}$ MDS, Assistant Professor, Department of Oral Medicine and Radiology, Sharad Pawar Dental College \& Hospital, Datta Meghe Institute of Medical Sciences (Deemed to be University), Sawangi (M), Wardha-442001, Maharashtra, India; 4MDS, MPhil \& PhD, Professor, Department of Oral Medicine and Radiology, Sharad Pawar Dental College \& Hospital, Datta Meghe Institute of Medical Sciences (Deemed to be University), Sawangi (M), Wardha-442001, Maharashtra, India.
\end{abstract}

\section{ABSTRACT}

Introduction: Betel nut consumption with or without tobacco and betel nut infested with Aspergillus flavours, generates free radicals and reactive oxygen species, which in turn induces a high rate of lipid peroxidation. Serum Malondialdehyde (MDA) is a highly recognized marker of lipid peroxidation. Objective: The present study was conducted to evaluate the effect of turmeric on increased lipid peroxidation by using serum MDA level \& as a surrogate outcome on clinical signs \& symptoms of oral submucous fibrosis (OSMF).

Material and Methods: Total of 150 subjects was divided into 4 groups. Group A: 30 subjects suffering from OSMF were treated with turmeric and counselled for stoppage of habit, Group B: 30 subjects suffering from OSMF were treated with turmeric and NOT counselled for the cessation of habit, Group C: 30 subjects suffering from OSMF did not keep on turmeric medication but counselled for stoppage of habit, Group D: 30 cases were betel-nut habitual without OSMF and Group E: 30 healthy control subjects.

Results and Observations: Statistically significant reduction of Serum MDA levels post-treatment in group A patients as compared to group B \& group C ( $p<0.05)$. Mean difference was observed as 9.00 in group A, 3.81 in group $B, 2.62$ in group $C$.

Conclusion: Increased serum Malondialdehyde (MDA) in OSMF would serve as a valuable surrogate marker in early diagnosis, treatment, and prognosis. The antioxidant properties of turmeric reduce the oxidative stress even with the effects of areca alkaloids and tobacco. Serum MDA level was decreased significantly in subjects taking turmeric medication for 4 weeks.

Key Words: OSMF, Betel-nut, Lipid peroxidation, Malondialdehyde

\section{INTRODUCTION}

Oral Submucous Fibrosis (OSMF) is a slowly progressive chronic condition of mainly involving non-keratinized mucosa of the mouth and characterized by fibrosis from epithelium to basement membrane; causing the inability to open mouth, blow/whistle, and speech \& eat. ${ }^{1}$ In Indian population OSMF is about $0.5 \% .^{2}$ Betel nut habit is the principal culprit in pathogenesis \& development of OSMF. Ingestion of chillies, nutritional deficiency, autoimmunity and genetic susceptibility, immunologic process and nutritional deficiencies are considered as cofactors. ${ }^{3}$
Interaction of free radicals \& reactive oxygen species (ROS) with lipid, DNA \& proteins is responsible for the degradation of proteins \& promote DNA strand breakage \& harms genomic structure. Lipid peroxidation is causing uninterrupted generation of free radicals responsible for tissue injury. Thus, generated damaging aldehydes, malondialdehyde (MDA) are the quality marker for lipid peroxidation. ${ }^{4,5}$ Oxidative stress is produced by ROS \& continuous transportation of oxygen to various parts of the body/organ and is safely detoxified by natural living antioxidants. ${ }^{6}$

\section{Corresponding Author:}

Dr. Mrunal Meshram, MDS, Assistant Professor, Department of Oral Medicine and Radiology, Sharad Pawar Dental College \& Hospital Datta Meghe Institute of Medical Sciences (Deemed to be University), Sawangi (M), Wardha-442001, Maharashtra, India; Email: drmrunalmeshram@gmail.com

ISSN: 2231-2196 (Print)

Received: 26.07 .2020
ISSN: $0975-5241$ (Online)

Revised: 28.06 .2020
Accepted: 04.08 .2020
Published: 07.12 .2020 
Turmeric is a polyphenol derived from roots of Curcuma longa plant. Turmeric is widely used in Indian system of Medicine Ayurveda. Curcumin (diferuloylmethane) main ingredient of turmeric is a carotenoid pigment, has antioxidant, analgesic, anti-inflammatory, anti-proliferative, anti-angiogenic, apoptosis-inducing, hepatoprotective \& antiseptic activities. ${ }^{7-10}$ Hence, we conducted this study for evaluating the effect of the whole turmeric on lipid peroxidation in patients with OSMF.

\section{MATERIAL AND METHODS}

This study was carried out in the Oral Medicine department, SPDC, DMIMS (DU) Wardha after obtaining ethical approval from the Institutional Ethics Committee. Detailed clinical examination of all patients was carried out \& recorded in structured proforma, after obtaining informed written consent. All patients were included by purposive sampling. A total of 150 subjects were recruited as follow-

Group A-30 suffering from OSMF on turmeric as well as counselled regarding stoppage of habit.

Group B-30 subjects suffering from OSMF on turmeric without counselling about the stoppage of habit. For these patients, counselling session was conducted after the study schedule.

Group C-30 subjects suffering from OSMF counselled for stoppage of habit but without turmeric medication. For these patients treatment protocol was started after study schedule.

Group D-Habitual controls, (30-Subjects Betel nut Habitual without OSMF) and

Group E-Healthy controls, (30- Subjects Without any detrimental Habit) were selected from persons accompanying with OSMF cases.

Inclusion Criteria was patient's above the age of 18 years clinically diagnosed as OSMF according to clinical \& functional staging. ${ }^{11}$ Raw turmeric was purchased \& turmeric powder was prepared using pulverization procedure. Curcumin level was estimated by HPLC \& $500 \mathrm{mg}$ powder containing $5.9 \mathrm{mg}$ of curcumin. $500 \mathrm{mg}$ turmeric capsules were prescribed twice daily for four weeks and evaluated at end of $4^{\text {th }}$ week for clinical signs and symptoms \& serum malondialdehyde (MDA) level. Venous blood samples were collected pre-treatment $\&$ post-treatment for MDA estimation. VAS scale was used encoding 10 scores according to severity of symptoms regarding patient's perception of Burning Sensation to spicy foods, Tightness of fibrous bands, and Roughness of mucosa, Ulceration, Tongue movement and inter-incisal distance both pre \& post treatment. Serum MDA was assayed by the modified Satoh Kei method (1978). ${ }^{12}$ MDA concentration was calculated as $\eta \mathrm{mol} / \mathrm{ml}$ pre \& post treat- ment in groups A, B, C and in group D \& E only single sample was estimated for MDA. Statistical Analysis was done by using descriptive and inferential statistics.

\section{RESULTS}

The mean age of OSMF patients in group A was found to be $32.26 \pm 12.47$ years, in group B $31.16 \pm 10.86$ years and group C $29.8 \pm 7.25$ years. The mean age in Group D was found to be $36.1 \pm 15.64$ years and in Group E it was $29.8 \pm$ 8.94 years. The mean age of all OSMF patients (Group A, B $\&$ C) was $31.07 \pm 10.36$ years. Most of the patients of OSMF were young adults in the age group of $18-45 \mathrm{yrs}$. $95 \%$ of patients were male and male to female ratio was 10:1. A maximum number of patients $83(92.22 \%)$ had a habit of Kharrah $\&$ betel nut chewing. Mean duration of habit in OSMF study subject (Group A, B \& C) was 7.66 \pm 6.66 years while in habitual control (Group-D) it was $5 \pm 2.78$ years (Table 1 and 2 ).

Pre-treatment Serum MDA level in OSMF patient, group A, B \& C was elevated [groupA-20.79 $\pm 7.15 \eta \mathrm{mol} / \mathrm{ml}$, group B-21.04 $\pm 5.84 \eta \mathrm{mol} / \mathrm{ml}$, \& group C- $22.72 \pm 6.33 \eta \mathrm{mol} / \mathrm{ml}]$ as compared to habitual control- Group D \& healthy control-Group E $[9.36 \pm 1.05 \eta \mathrm{mol} / \mathrm{ml} \& 5.80 \pm 1.77 \eta \mathrm{mol} / \mathrm{ml}$ respectively] and showed statistical significance $(\mathrm{p}=0.000)$ (Table-3).

Significant decrease in post-treatment Serum Malondialdehyde levels was found in group-A patients (mean difference-9.00) as compared to groups-B (mean difference-3.81) $\&$ groups-C (mean difference-2.62) (Table 4). There was a significant increase in inter-incisal mouth opening, reduction in burning sensation, reduction in the tautness of fibrous bands, and reduction in ulcerations in Group- A in contrast to Group- B after giving whole turmeric capsules as a part of medication along with stoppage of habit $(\mathrm{p}<0.05)$ (Tables-5).

\section{DISCUSSION}

OSMF is a deliberating condition with considerable malignant potential. Arecoline is the principal alkaloid responsible for the pathogenesis of OSMF includes fibroblastic proliferation and increased collagen formation. ${ }^{13}$ Aflatoxin contaminated betel nuts along with alkaloids intensifies lipid peroxidation and decreasing enzymatic and non-enzymatic antioxidants. ${ }^{14}$ The free radical especially Hydroxyl radical is an extremely aggressive oxidant that can damage most of the biological molecule of the cell by lipid peroxidation, oxidative modification of proteins and DNA base alteration. MDA is a frequently used biomarker that provides overall information regarding lipid peroxidation. ${ }^{15}$ Evaluation of serum MDA level may be used as a potential surrogate marker for evaluating disease process in Oral submucous fibrosis. 
In phase-I clinical trials, it is reported that curcumin $12 \mathrm{gm} /$ day is well tolerated. ${ }^{16}$ Its been signified that curcumin has superior scavenging property as compared to beta carotene on superoxide radicals, free radicals and lipid peroxidation. ${ }^{17}$ Both turmeric oil and curcumin could work in an alliance of their anti-inflammatory and anti-cancer effects. ${ }^{18,19}$ Soma Gupta et al., observed the raised Plasma MDA levels in OSMF patients $(3.3 \pm 0.4 \eta \mathrm{mol} / \mathrm{ml})$ compared to healthy controls $(2.4+0.5 \eta \mathrm{mol} / \mathrm{ml}) ;(P<0.001)$. Decreased post-treatment mean MDA and increase in beta-carotene level were also observed in the same group of patients $(P<0.001){ }^{20,21}$ Increased mean serum malondialdehyde level in Oral Precancer \& Cancer $9.33 \pm 4.89 \eta \mathrm{mol} / \mathrm{ml}$ and $14.34 \pm 1.43 \eta \mathrm{mol} /$ $\mathrm{ml}$ respectively as compared to control $5.107 \pm 2.32 \mathrm{\eta mol} /$ ml. ${ }^{22}$ In the present study, pretreatment serum MDA level was elevated in OSMF patients (group A, B \& C) as compared to controls (Table $3 \& 4$ ). This suggests the role of lipid peroxidation i.e. oxidative stress \& ROS in the pathogenesis of oral submucous fibrosis. Similarly, there was a significant reduction in serum MDA level post-treatment in OSMF groups $(\mathrm{A}, \mathrm{B}, \mathrm{C})(\mathrm{p}<0.000)$, with more reduction, was observed in Group A in contrast to Group B (Table-4). This showed that stoppage of habit with turmeric medication had a significant effect on lipid peroxidation (MDA) \& clinical signs \& symptoms. In group B patients, turmeric medication showed its antioxidant $\&$ anti-inflammatory properties without cessation of the habit. This explains that betel nut alkaloid induced oxidative stress is relieved by the whole turmeric which is correlated with MDA level. On comparing habitual \& healthy controls (groups D \& E), increased MDA level in habitual controls indicates that lipid peroxidation is initiated by betel nut products with or without tobacco well before clinically evident disease process of OSMF. Kuttan Ramadasan et al., used ethanol extract of turmeric as a topical therapy in cancer of oral cavity and reported improvement in $64.80 \%$ of the patients. ${ }^{23}$

Turmeric has been showing fibrinolytic action in iron-induced hepatotoxicity and improvement in liver functions AST, ALT \& ALP to the normal level by inclusion of dietary turmeric, chilli pepper, cardamom, or clove in daily food of rat. ${ }^{24}$ Manjunatha and Srinivasan demonstrated that dietary turmeric and capsaicin in chilli pepper notably repressed iron-induced Low-Density Lipoprotein (LDL), in vivo and copper-induced oxidation of Low-Density Lipoprotein, in vitro. The protecting effectivity of combination of turmeric and capsaicin on LDL oxidation was significantly higher than that of single components..$^{25}$ Balwant Rai et al., observed the significant symptomatic relief and reduction in the clinical size of oral Leukoplakia, treated with curcumin. ${ }^{26}$

In the given study significant reduction of serum MDA levels was observed between pre \& post-treatment with twice-daily $500 \mathrm{mg}$ turmeric capsules at end of 4 weeks. Significant improvement in clinical signs \& symptoms were observed in group A as compared to B \& C (Table-5). Sharma C et al. demonstrated that curcumin remarkably reduced nicotine acquired nitrosamine ketone cyclooxygenase- 2 in oral pre-malignant as well as malignant cells in vitro. ${ }^{27}$ Jayashree et al. observed that turmeric extract and turmeric oil (TO) in doses of $0.6 \mathrm{ml}$ and $1.0 \mathrm{ml}$ for 3 months of continuous daily intake had preventive properties against chemically generated carcinomas in lab animals. ${ }^{28}$ Deepa Das et al., treated OSMF patients with curcumin \& Turmeric oil for one month and reported significant improvement in clinical signs and symptoms. ${ }^{29}$ Mrunal Meshram et al. used turmeric ointment twice daily for 03 months in oral submucous fibrosis patients and observed significant improvement in clinical symptoms. ${ }^{30,31}$ Bhide \& Jakhi put out relief from clinical symptoms and refinement in the opening of the jaw with turmeric extract and its oil in total of 30 cases of oral submucous fibrosis. ${ }^{32}$ Similarly in present study statistically significant increase in inter-incisal opening \& reduction in burning sensation was observed in group A \& B but more significant in group A patients who were on turmeric medication with stoppage of habit (Table-5). Deng YT et al. observed dose-dependent complete inhibition of arecoline induced connective tissue growth factor (CTGF) in their in vivo study on human buccal mucosal fibroblasts treated with curcumin. ${ }^{33}$ This suggests its fibrinolytic activity. Similarly, in the present study, a significant reduction in the toughness of fibrous bands i.e. clinical improvement in the elasticity of oral mucosa was observed in group-A patients as compared to groups B \& C \& was directly proportional to the level of serum MDA (Table-4 \& 5). Curcumin also inhibits cell proliferation in fibroblast and myofibroblast; disturbs cell cycle, impel apoptosis as well as reduces decreases the generation type I and III collagen in myofibroblast. ${ }^{34-36}$ Prior types of research have proved that turmeric can interfere at varied phases of the cell cycle through suppression of DNA synthesis, downregulation of cyclin D1, provocation of $\mathrm{p} 53$ and cyclin-dependent kinase inhibitors, as well as retardation of NF- $\kappa$ B. ${ }^{37-39}$

Prakasunand $\mathrm{C}$ et al., observed in 54 cases of peptic ulcer who were given 2 capsules of turmeric (300 mg each) 5 times daily for 4 weeks \& reached a healing rate of $48 \%{ }^{40}$ Similarly in the present study, we observed reduction in ulceration of oral mucosa in $40 \%$ of OSMF patients (groups A \& B). Significant reduction is observed in group A after giving turmeric capsules \& with stoppage of habit $(\mathrm{p}<0.05)$ (Table-5). The curing effects of turmeric has been illustrated in Ayurveda and further traditional branches and confirmed by several experimental studies that it can arrest of carcinogenesis and also capable for reversal of the OSMF. ${ }^{16,41,42}$

Reduced bioavailability of oral curcumin is related with its rapid metabolism due to its less effective conjugated form ${ }^{43}$ but Robert CG Martin et al. suggested that of curcumin in precursor form can yield resistance to the fast metabolism which takes place in the upper gastrointestinal tract and 
comes up with superior organ penetrance than that of with curcumin alone. ${ }^{44}$ Therefore, in the present study whole turmeric could be more beneficial as it contains curcumin, turmeric oil \& curcuminoids which through the enzymatic process in the gastrointestinal tract got absorbed more efficiently.

Table 1: Demographic Characteristics of Study \& Control Groups

\begin{tabular}{|c|c|c|c|c|c|}
\hline Characteristics & GP-A $(n=30)$ & GP-B $(n=30)$ & GP-C $(n=30)$ & GP-D $(n=30)$ & GP-E $(n=30)$ \\
\hline \multicolumn{6}{|l|}{ Age in Years } \\
\hline Mean & 32.26 & 31.16 & 29.82 & 36.15 & 29.80 \\
\hline SD & 12.47 & 10.86 & 7.25 & 15.64 & 8.94 \\
\hline Range & $18-60$ & $19-62$ & $18-45$ & $16-65$ & $19-55$ \\
\hline \multicolumn{6}{|l|}{ Gender (\%) } \\
\hline Male & 93.33 & 96.66 & 90 & 90 & 70 \\
\hline Female & 6.66 & 3.33 & 10 & 10 & 30 \\
\hline M:F Ratio & & & $10: 1$ & & \\
\hline
\end{tabular}

Table 2: Habit Characteristics of study \& Habitual Control

\begin{tabular}{|c|c|c|c|c|}
\hline Characteristics & GP-A $(n=30)$ & GP-B $(n=30)$ & GP-C $(n=30)$ & GP-D $(n=30)$ \\
\hline \multicolumn{5}{|l|}{ Type of Habit } \\
\hline Kharrha \& Betel Nut & 20 & 19 & 23 & 21 \\
\hline Kharrha \& Gutkha & 3 & 2 & 2 & 6 \\
\hline Betel Nut & 7 & 9 & 5 & 3 \\
\hline \multicolumn{5}{|c|}{ Duration of Habit (years) } \\
\hline Mean & 9.96 & 6.93 & 6.11 & 5 \\
\hline SD & 12.36 & 4.63 & 3 & 2.78 \\
\hline Range & Мay-зо & May-2o & May-15 & 05-Oct \\
\hline
\end{tabular}

Table 3: Comparison of Mean Serum Malondialdehyde levels in all groups

\begin{tabular}{llccc} 
Groups & $\mathrm{N}$ & Mean Serum MDA (Pretreatment) & SEM \pm SD & Std. Deviation \\
Group-A & 30 & 20.7997 & 1.30582 & 7.15227 \\
Group-B & 30 & 21.047 & 1.06777 & 5.8484 \\
Group-C & 30 & 22.72 & 1.15575 & 6.3303 \\
Group-D & 30 & 9.365 & 0.33391 & 1.05592 \\
Group-E & 30 & 5.805 & 0.56036 & 1.77202 \\
\hline
\end{tabular}

Table 4: Comparison of Mean Serum Malondialdehyde levels at pre and post-treatment in study groups $(\mathrm{N}=30)$

\begin{tabular}{llcccccc} 
Groups & Mean & Std. Deviation & $\begin{array}{c}\text { Std. Error } \\
\text { Mean }\end{array}$ & Mean Difference & t-value & p-value \\
Group A & Pre t/t & 20.79 & 7.15227 & 1.3058 & 9.00867 & 13.193 & 0 \\
& Post t/t & 11.79 & 4.76103 & 0.8692 & & & S,p<0.05 \\
Group B & Pre t/t & 21.04 & 5.8484 & 1.0677 & 3.815 & 13.312 & 0.000 S,p<0.05 \\
& Post t/t & 17.23 & 5.35388 & 0.9774 & & & \\
Group C & Pre t/t & 22.72 & 6.3303 & 1.1557 & 2.62967 & 15.734 & 0.000 S,p<0.05 \\
& Post t/t & 20.09 & 6.07482 & 1.1091 & & & \\
\hline
\end{tabular}


Table 5: Clinical Pre and post Treatment Characteristics of Study Group

\begin{tabular}{|c|c|c|c|c|c|c|}
\hline \multirow[t]{2}{*}{ Characteristics } & \multicolumn{2}{|c|}{ Group A $n=30$} & \multicolumn{2}{|c|}{ Group B $n=30$} & \multicolumn{2}{|c|}{ Group $C \mathrm{n}=30$} \\
\hline & Pre $T / t$ & Post $\mathrm{T} / \mathrm{t}$ & Pre $T / t$ & Post $\mathrm{T} / \mathrm{t}$ & Pre $T / t$ & Post $\mathrm{T} / \mathrm{t}$ \\
\hline \multicolumn{7}{|c|}{ Inter incisal mouth opening } \\
\hline Mean & 25.33 & 27.43 & 23.4 & 24.33 & $25 \cdot 3$ & 26.9 \\
\hline SD & 7.01 & 6.8 & $7 \cdot 48$ & 7.5 & 8.52 & 8.59 \\
\hline Mean difference & \multicolumn{2}{|c|}{2.1} & \multicolumn{2}{|c|}{0.93333} & \multicolumn{2}{|c|}{1.6} \\
\hline Pvalue & \multicolumn{2}{|c|}{ o } & \multicolumn{2}{|c|}{ o } & \multicolumn{2}{|c|}{ o } \\
\hline \multicolumn{7}{|l|}{ Burning mucosa } \\
\hline Mean & 3.6 & 1.5333 & 3.3 & 2.4667 & 3.3 & 1.8 \\
\hline SD & 1.13259 & 1.22428 & 0.83666 & 0.9732 & 0.70221 & 0.80516 \\
\hline Mean difference & \multicolumn{2}{|c|}{2.06667} & \multicolumn{2}{|c|}{0.83333} & \multicolumn{2}{|c|}{1.5} \\
\hline Pvalue & \multicolumn{2}{|c|}{ o } & \multicolumn{2}{|c|}{ o } & \multicolumn{2}{|c|}{ o } \\
\hline \multicolumn{7}{|c|}{ Tautness of fibrous bands } \\
\hline Mean & 2.7 & 1.46 & 2.43 & 1.83 & 2.56 & 1.76 \\
\hline SD & 0.70221 & 0.57135 & 0.72793 & 0.69893 & 0.62601 & 0.85836 \\
\hline Mean difference & \multicolumn{2}{|c|}{1.23333} & \multicolumn{2}{|c|}{0.6} & \multicolumn{2}{|c|}{0.8} \\
\hline Pvalue & \multicolumn{2}{|c|}{ o } & \multicolumn{2}{|c|}{ o } & \multicolumn{2}{|c|}{ o } \\
\hline \multicolumn{7}{|l|}{ Tongue movement } \\
\hline Mean & $(20)^{*} 3.0667$ & 2.4667 & $(17)^{*} 2.7333$ & 2.4333 & $(21)^{*} 2.100$ & 1.8333 \\
\hline SD & 1.201 & 1.166 & 1.142 & 1.006 & 1.373 & 1.205 \\
\hline Mean difference & \multicolumn{2}{|c|}{0.6} & \multicolumn{2}{|c|}{0.3} & \multicolumn{2}{|c|}{0.26667} \\
\hline P value & \multicolumn{2}{|c|}{$\mathrm{o}$} & \multicolumn{2}{|c|}{0.001} & \multicolumn{2}{|c|}{0.003} \\
\hline Oral ulceration & & & & & & \\
\hline Mean & $(12)^{*} 1.36$ & 0.16 & $(9)^{*} 0.86$ & 0.46 & $(15)^{*} 0.56$ & 0.13 \\
\hline SD & 0.96431 & 0.37905 & 0.68145 & 0.57135 & 0.67891 & 0.34575 \\
\hline Mean difference & & & & & & \\
\hline P value & & & & & & \\
\hline
\end{tabular}

()$^{*}=$ number of cases

\section{CONCLUSION}

Serum MDA measures were observed to be elevated in oral submucous fibrosis when equating to habitual \& healthy control. Individuals, on turmeric medication for 4 weeks showed significantly reduced MDA level. Thus, the level of lipid peroxidation i.e. oxidative stress is decreased after oral administration of turmeric. Similarly, the oral submucous fibrosis patients are relieved from clinical signs \& symptoms particularly improved inter-incisal distance \& toughness of fibrous bands thus turmeric may act as an anti-fibrotic.

Turmeric has excellent antioxidant, anti-proliferative, antiinflammatory, antiviral, antibacterial, antifungal, analgesic, anti-allergic and antiseptic effects which signify its potential use in treatment oral Potentially Malignant Disorders (PMDs) like OSMF. Thus, this choice of therapy accompanied with stoppage of habit is beneficial, affordable and noninvasive to patients with OSMF to control the malignant transformation.

\section{ACKNOWLEDGEMENT}

Our thanks are due to the Dr. R.M. Borle; Vice-chancellor of the University for allowing conducting this study. Dr.Bharat Rathi, Professor, Department of Rasashastra and Bhaishajya Kalpana, Mahatma Gandhi Ayurved College, Hospital And 
Research Centre, Salod; for the preparation of whole turmeric extract capsules. Authors acknowledge the immense help received from the scholars whose articles are cited and included in references to this manuscript. The authors are also grateful to authors/editors/publishers of all those articles, journals and books from where the literature for this article has been reviewed and discussed.

Conflict of interest: All authors declare that there are no conflicts of interest.

\section{Financial support: Nil}

\section{REFERENCES}

1. Pindborg JJ, Satyarati MS. Oral submucous fibrosis. Oral Surg Oral Med Oral Pathol 1966; 22:764-779.

2. Raina C, Raizada RM, Chaturvedi VN, Harinath BC, Puttewar MP, Kennedy AK. Clinical profile and serum beta carotene levels in oral submucous fibrosis. Indian J Otolaryngol Head Neck Surg 2005 Jul; 57(3): 191-195.

3. Babu S, Bhat RV, Kumar PU, Sesikaran B, Rao KV, Aruna P, et al. A comparative clinicopathological study of oral submucous fibrosis in habitual chewers of pan masala and betel quid. J Toxicol Clin Toxicol 1996; 34(3):317-22.

4. Antonio Ayala et al., Lipid Peroxidation: Production, Metabolism, and Signaling Mechanisms of Malondialdehyde and 4-Hydroxy-2-Nonenal. Oxid Med Cell Longev 2014; 2014:360438.

5. Nielsen F, Mikkelsen BB, Nielsen JB, Andersen HR, Grandjean P. Plasma malondialdehyde as biomarker for oxidative stress: Reference interval and effects of life-style factors. Clin Chem 1997; 43:1209-14.

6. Gutteridge John M.C. Lipid peroxidation and Antioxidants as Biomarkers of Tissue Damage. Clin Chem 1995; 41: 1819-1828.

7. Krishnaswamy K. Turmeric-a potential anticancer agent. Amala Res Bull 1998; 18:23-28.

8. Atsumi T, Murakami Y, Shibuya K, Tonosaki K, Fujisawa S. Induction of cytotoxicity and apoptosis and inhibition of cyclooxygenase- 2 gene expression, by curcumin and its analog, alpha-diisoeugenol. Anticancer Res 2005; 25:4029-4036.

9. Yvonne G. Lin, Ajaikumar B. Kunnumakkara. Curcumin inhibits tumour growth and angiogenesis in ovarian carcinoma by targeting the nuclear factor- $\kappa \mathrm{B}$ pathway. Clin Cancer Res 2007; 13 (11):3423-3430.

10. Siwak DR, Shishodia S, Aggarwal BB. Curcumin-Induced Antiproliferative and Proapoptotic Effects in Melanoma Cells have Associated with Suppression of IkB Kinase and Nuclear Factor $\mathrm{KB}$ Activity and Are Independent of the B-Raf/Mitogen-Activated/Extracellular Signal-Regulated Protein Kinase Pathway and the Akt Pathway. Cancer 2005; 104:879-90.

11. Haider SM, Merchant A, Fikree F, Rahbar M. Clinical and functional staging of oral submucous fibrosis. Br J Oral Maxillofacial Surg 2000; 38(1):12-15.

12. Satoh K, Serum lipid peroxide in cerebrovascular disorders determined by a new colourimetric method. Clin Chim Acta 1978; 90:37-43.

13. Maher R, Lee AJ, Warnakulasuriya KAAS, Lewis JA, Johnson NW. Role of areca nut in the causation of Oral Submucous Fibrosis: A case-control study in Pakistan. J Oral Pathol Med 1994; 23:65-69.

14. El-Gibaly I, Meki A, Abdel-Ghaffar SK. Novel B melatoninloaded chitosan microcapsules: in vitro characterization and anti-apoptosis efficacy for aflatoxin B1-induced apoptosis in rat liver. Int J Pharmacol 2003; 260(1):5-22.

15. Draper HH, Haley M. Malondialdehyde determination as index of lipid peroxidation. Methods Enzymol 1990; 186:421-31.

16. AL Cheng, $\mathrm{CH}$ Hsu, Lin JK. Phase-I clinical trial of curcumin, a chemopreventive agent, in patients with a high risk of premalignant lesions. Anticancer Res 2001; 21: 2895-900.

17. Rao SD, Chandrasekhar AN, Satyanarayanan MN, Srinivasan M. Effect of curcumin on serum and liver cholesterol levels in the rat. J Nutrition 1970; 100:1307-15.

18. Hongyu Zhou, Christopher S. Beevers. Targets of curcumin. Curr Drug Targets 2011; 12(3): 332-347.

19. Tejasvi A, Bangi BB, Geetha P. Estimation of serum superoxide dismutase and serum malondialdehyde in oral submucous fibrosis: A clinical and biochemical study. J Cancer Res Therap 2014; 10(3):722-725.

20. Gupta S, Reddy MVR, Harinath BC. Role of Oxidative Stress and Antioxidants in Aetiopathogenesis and Management of Oral Submucous Fibrosis. Indian J Clin Biochem 2004; 19 (1):138141.

21. Metkari S B, Tupkari J V, Barpande S R. An estimation of serum malondialdehyde, superoxide dismutase and vitamin A in oral submucous fibrosis. J Oral Maxillofacial Pathol 2007; 11:23-27.

22. Chole R, Patil RN, Basak A, Palandurkar K, Bhowate R. Estimation of serum malonaldehyde in oral cancer and Precancer and its association with healthy individuals, gender, alcohol, and tobacco abuse. J Can Res Ther 2010; 19 (6):487-91.

23. Kuttan R, Sudheeran PC, Josph CD. Turmeric and curcumin as topical agents in cancer therapy. Tumorogenesis 1987; 2:28-29.

24. Sadeek EA, Fatma H, El-Razek A. The Chemo-Protective Effect of Turmeric, Chili, Cloves and Cardamom on Correcting Iron Overload-Induced Liver Injury, Oxidative Stress and Serum Lipid Profile in Rat Models. J Am Sci 2010; 6(10):702-712.

25. Manjunatha H., Srinivasan K. Protective effect of dietary curcumin and capsaicin on induced oxidation of low-density lipoprotein, iron-induced hepatotoxicity and carrageenan-induced inflammation in experimental rats. FEBS J 2006; 273(19)45:2837.

26. Rai B, Kaur J, Jacobs R. Possible action mechanisms of curcumin in precancerous lesions based on serum and salivary markers of oxidative stress. J Oral Sci 2010; 52:251-56.

27. Sharma C, Kaur J, Shishodia S, Aggarwal BB, Ralhan R. Curcumin downregulates smokeless tobacco-induced NF- $\mathrm{kB}$ activation and COX-2 expression in human oral premalignant and cancer cells. Toxicology 2006; 228:1-15.

28. Joshi J, Ghaisas S, Vaidya A, Vaidya R, Kamat DV, Bhide S. Early Human Safety Study of Turmeric Oil (Curcuma longa Oil) Administered Orally in Healthy Volunteers. J Assoc Physicians India 2003; 51:1055-60.

29. Das AD, Balan A, Sreelatha KT. Comparative study of the efficacy of curcumin and turmeric oil as chemopreventive agents in oral submucous fibrosis: A clinical and histopathological evaluation. J Indian Acad Oral Med Radiol 2010; 22: 88-92.

30. Meshram M, Bhowate RR, Madke B, Sune R. Evaluation of the effect of ultrasound physiotherapy interventions in combination with local application of aloe-vera and turmeric gel in the management of oral submucous fibrosis. J Dental Investig 2018; 1(1): 16-33.

31. Lanjekar AB, Bhowate RR, Bakhle S, Narayane A, Pawar V, Gandaguleet R. Comparison of Efficacy of Topical Curcumin Gel with Triamcinolonehyaluronidase Gel Individually and in Combination in the Treatment of Oral Submucous Fibrosis. J Contemp Dent Pract 2020; 21(1):83-90. 
32. Bhide SV, Jakhi SD. Clinical studies on turmeric treatment of precancerous oral lesions. Proceedings of XVI International Cancer Congress Abstract, 1994:351.

33. Deng YT, Chen HM. Arecoline-stimulated connective tissue growth factor production in human buccal mucosal fibroblasts: Modulation by curcumin. Oral Oncology 2009; 45:99-105.

34. Utsunomiya H, Tilakaratne WM, Oshiro K, Maruyama S, Suzuki M, Ida-Yonemochi H. Extracellular matrix remodeling in oral submucous fibrosis: its stage-specific modes revealed by immune-histochemistry and in situ hybridization. J Oral Pathol Med 2005; 34, 498-507.

35. Kuttan R, Sudheeran PC, Joseph CD. Turmeric and curcumin as topical agents in cancer therapy. Tumor 1987; 73:29-31.

36. Zhang SS, Gong ZJ, Li WH, Wang X, Ling TY. Antifibrotic Effect of Curcumin in TGF- $\beta 1$-Induced Myofibroblasts from $\mathrm{Hu}-$ man Oral Mucosa. Asian Pac J Cancer Prev 2012;13(1):289-94.

37. Karunagaran D, Joseph J, Kumar TR. Cell growth regulation. Adv Exp Med Biol 2007; 595: 245-268.

38. Keane MP, Strieter RM, Belperio JA. Mechanisms and mediators of pulmonary fibrosis. Crit Rev Immunol 2005; 25: 429463.
39. Kuttan G, Kumar KB, Guruvayoorappan C, Kuttan R. Antitumor, anti-invasion, and antimetastatic effects of curcumin. Adv Exp Med Biol 2007; 595:173-184.

40. Prackasunand C, Indrasukhsri B, Leethochawalit M, Hungspreugs K. Phase II clinical trial on effect of long turmeric (Curcuma longa Linn) on healing of peptic ulcer. Southeast Asian J Trop Med Public Health 2001; 32:208-15.

41. Bharat B. Aggarwal, Curcumin Derived from Turmeric (Curcuma longa): a Spice for All Seasons; Phytopharmaceuticals in Cancer Chemoprevention 2005 by CRC Press LLC.

42. Sandeep A. Lawande, Therapeutic applications of turmeric (Curcuma longa) in dentistry: A promising future. J Pharm Biomed Sci 2013; 27(27): 586-591.

43. Ireson CR, Jones DJ, Orr S, Coughtrie MW, Boocock DJ, Williams ML, et al. Metabolism of the cancer chemopreventive agent curcumin in human and rat intestine. Cancer Epidemiol Biomarkers Prev 2002; 11:105-111.

44. Robert CG Martin, Harini S Aiyer, Daniel Malik, and Yan Li. Effect on Pro-inflammatory and Antioxidant Genes and Bioavailable Distribution of Whole Turmeric vs Curcumin: Similar Root but Different Effects. Food Chem Toxicol. 50(2): 227-231. 